\title{
Health Locus of Control and Assimilation of Cervical Cancer Information in Deaf Women
}

\author{
Regina Wang • Arianna A. Aldridge • \\ Vanessa L. Malcarne • Sun Choe • Patricia Branz • \\ Georgia Robins Sadler
}

Received: 1 October 2009 /Revised: 22 December 2009/Accepted: 22 January 2010/Published online: 6 March 2010

(C) The Author(s) 2010. This article is published with open access at Springerlink.com

\begin{abstract}
This study assessed the relationship between Deaf women's internal health locus of control (IHLC) and their cervical cancer knowledge acquisition and retention. A blind, randomized trial evaluated Deaf women's $(N=130)$ baseline cancer knowledge and knowledge gained and retained from an educational intervention, in relation to their IHLC. The Multidimensional Health Locus of Control scales measured baseline IHLC, and a cervical cancer knowledge survey evaluated baseline to post-intervention knowledge change. Women's IHLC did not significantly predict greater cervical cancer knowledge at baseline or
\end{abstract}

R. Wang • A. A. Aldridge • V. L. Malcarne $\cdot$ S. Choe $\cdot$ P. Branz $\cdot$

G. R. Sadler

Moores UCSD Cancer Center,

La Jolla, CA, USA

G. R. Sadler

Department of Surgery, UCSD School of Medicine,

La Jolla, CA, USA

R. Wang $\cdot$ S. Choe

UCSD School of Medicine,

La Jolla, CA, USA

V. L. Malcarne

Department of Psychology, San Diego State University,

San Diego, CA, USA

A. A. Aldridge $\cdot$ V. L. Malcarne

SDSU/UCSD Joint Doctoral Program in Clinical Psychology,

San Diego, CA, USA

G. R. Sadler $(\bowtie)$

Clinical Professor of Surgery, UCSD School of Medicine,

Associate Director for Community Outreach,

Rebecca and John Moores UCSD Cancer Center,

3855 Health Sciences Drive \#0850,

La Jolla, CA 92093-0850, USA

e-mail: gsadler@ucsd.edu over time. IHLC does not appear to be a characteristic that must be considered when creating Deaf women's cancer education programs.

Keywords Multidimensional Health Locus of Control (MHLC) · American Sign Language (ASL) - Deaf .

Cervical cancer $\cdot$ Education

\section{Introduction}

Cervical cancer is an increasingly controllable disease through prevention (sexual abstinence and human papillomavirus (HPV) vaccination), early detection (adherence to recommended screening guidelines for Pap tests), and prompt, appropriate treatment [1-4]. Thus, women's access to and use of cervical cancer knowledge and services are vital to their survival [5]. Deaf women are among the minority groups that have been shown to experience barriers to accessing health information and services due to language and cultural barriers [6]. This paper explores the relationship between Deaf women's internal health locus of control (IHLC) and their possession, acquisition, and retention of cervical cancer knowledge.

\section{Background on the Deaf Community}

The Deaf community experiences many of the same language and cultural barriers to accessing health information and care as do other minority communities $[7,8]$. The word Deaf with a capital " $D$ " is used to signify those people who share a common language (American Sign Language (ASL)) and culture (Deaf culture), as opposed to a lower case "d" which is an audiological term. Within this community, English literacy levels average between fourth 
and fifth grade because English is learned as a second language, if it is learned at all [9-11]. Members of the Deaf community possess varying levels of ASL, lip reading, and note writing skills and combine their skills to achieve optimum communication.

Compounding this literacy barrier is the severe shortage [12] of healthcare professionals and public health educators who are proficient in ASL $[8,13,14]$. This makes the mainstream health education strategies less effective for the Deaf community than for the general public and can lead to misconstrued health information among Deaf individuals [15-18]. The communication barriers experienced by Deaf women are compounded by cultural differences $[8,13,15$, 18-20] and mistrust of the medical system that further deter Deaf women from accessing vital health services [7, 13, 14, $16,17,21,22]$. These factors place Deaf women at greater risk for receiving medical care late for preventable or treatable illnesses and consequently, increase their odds of greater morbidity, sequelae, and mortality rates [13].

\section{Internal Health Locus of Control}

It has long been established that people's perceived ability to control their health influences their efforts to accumulate and use health knowledge [23]. Social learning theory predicts that people will participate in goal-directed behavior if they value the goal and believe that their actions will help them achieve that goal $[24,25]$. Thus, a woman would be expected to seek information about a health-threatening illness if she values her health and believes that changing her behavior will lead to better health [26]. People with a strong IHLC believe that their behaviors determine their health status. They are more likely to seek information about health-threatening conditions and engage in healthier behaviors, such as disease prevention, to maintain their health $[23,27,28]$. Women with high IHLC, i.e., who believe that they control their own health, have been shown to be more likely to engage in cervical cancer screening $[29,30]$.

\section{Cervical Cancer Education for Deaf Women}

Prior research has shown that minority women and women with disabilities are less likely to receive a Pap smear within the last 12 months or to have continuity in their medical care [3, 17, 31]. A new cervical cancer education video (Cervical Cancer: Catch It Early and Save Your Life) was specifically developed to help Deaf women reduce their risk of discovering their cervical cancer at later stages by improving their access to cancer education. The information is presented in ASL with open captioning and voice-over in English so it can be shared with people who are hard of hearing, as well as hearing loved ones. It was made without competing background music to make the audio more accessible for people who are hard of hearing (http://cancer.ucsd.edu/deafinfo).

Members of this research team recently published the results of a blind, randomized education trial to evaluate the impact of the partnership's new cervical cancer education video among a cohort of Deaf women who rely upon ASL as their preferred mode of communication [32]. Given the dearth of health education programs available in ASL, the women in the control group were offered the opportunity to cross over into the experimental group after completing their participation in the control group (see Fig. 1. Crossover Study Design). Once they crossed over, the women from the control group followed the same protocol as the group of women who had been randomized into the experimental group. The study showed that once the women had viewed the video, their cervical cancer knowledge increased, and the increase was statistically, significantly greater than the pre- to post-intervention knowledge change for the control group before their crossover.

The women in this study also completed an ASL version of the Multidimensional Health Locus of Control (MHLC) scales, a widely used questionnaire that measures healthrelated control beliefs, including IHLC. In order to determine whether internality of health control beliefs influenced the acquisition of cervical cancer knowledge, the present study assessed the relationship between IHLC and cervical cancer knowledge for the sample of participants in both the original experimental group and the

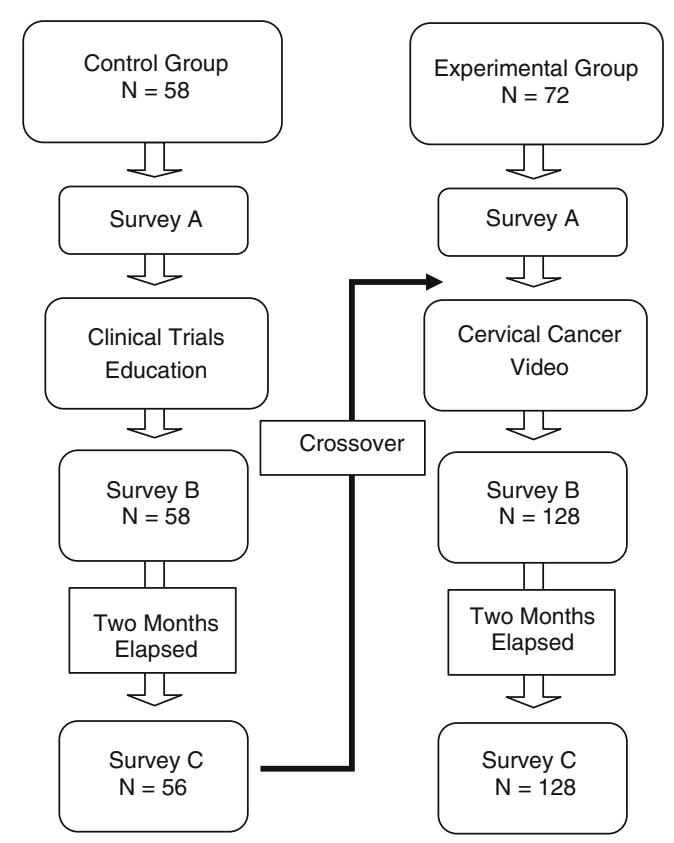

Fig. 1 Crossover study design layout [32] 
crossover experimental group combined. The relationship of IHLC to both baseline cancer knowledge and acquisition of knowledge following exposure to the cervical cancer education video were analyzed.

This study tested two hypotheses:

Hypothesis 1. Deaf women with higher IHLC will possess a significantly $(p<0.05)$ higher baseline of cervical cancer knowledge.

Hypothesis 2. Deaf women with higher IHLC will gain and retain significantly $(p<0.05)$ more cervical cancer knowledge after a single viewing of the cervical cancer education video that was offered in ASL with open captioning.

\section{Methods}

\section{Study Design}

The study team invited adult Deaf women from Southern California who used ASL as their preferred mode of communication to participate in the evaluation of an education program intended to improve the health and well being of the Deaf community, offered in ASL and supplemented with open captioning. At baseline, 130 Deaf women completed the written human subjects consent form required to join in the study; 58 were randomized to the control group and 72 to the experimental group. Two women in the control group were lost to follow-up and could not be located to learn their reasons for dropping out of the study. When the remaining 56 control group women were invited to cross over into the experimental group after completing their time in the control group, all of them did so, resulting in 128 women in the combined experimental group.

\section{Measures}

MHLC scales The MHLC scales measure health-related control beliefs $[33,34]$. The IHLC scale measures the strength of a person's belief that he or she possesses control over his or her health. An ASL version of the MHLC scales was created and recorded on videotape via forward and backward translation and reconciliation [35] and validated [36]. As the result of confirmatory factor analysis that was conducted to establish the validity of the ASL version of the MHLC for use with members of the Deaf community, one of the original items (i.e., "When I get sick, I am to blame") was removed from scoring of the IHLC subscale due to poor loading on the scale [36]. Thus, the IHLC scale score used in this study was based on five rather than the original six items. Each item is rated on a 6-point scale from $1=$ "strongly disagree" to $6=$ "strongly agree," for a total IHLC score ranging from 5 to 30 points, with higher scores representing more internal control over health.

Cervical Cancer Knowledge Knowledge about cervical cancer was measured using a 13-question survey [6]. Five questions asked about general knowledge of cancer (e.g., Which cancer occurs the most often in women?); an additional eight true/false items tested knowledge about cancer and cervical cancer screening (e.g., Human papillomavirus or HPV is the virus that causes most cases of cervical cancer). A total score, representing the number of items answered correctly, was generated and used in the analysis. This total score has demonstrated validity (i.e., sensitivity to change) in the randomized controlled trial [6].

\section{Statistical Analyses}

For purposes of analysis, higher and lower IHLC groups were created, based on a median split of the data for the IHLC scale $($ median $=25)$. Thus, those participants who scored 25 or above were deemed to have higher IHLC, and those scoring 24 or below were considered to have lower IHLC. Because of restricted range, this latter group of participants could not be considered to be truly low in IHLC; rather, the "lower" group average falls at about the midpoint of the scale, reflecting moderate internality of health control. A mixed model analysis was performed to analyze the repeated measures data of cervical cancer knowledge at baseline (i.e., first wave of data collection for all participants), at Time Two (i.e., immediately following the video intervention), and again at Time Three (i.e., 2 months after participants viewed the cervical cancer video intervention). Analyses were completed in SPSS 15 (Version 1.0). First, the main effect of higher IHLC (coded as values $\geq 25$ ) relative to lower IHLC (coded as values $\leq 24)$ was examined in relation to participants' baseline cervical cancer knowledge. The main effects of IHLC and time on cervical cancer knowledge at Time Two and Time Three were examined, with the significance of the interaction of time and IHLC of primary interest.

\section{Results}

\section{Sample Description}

The ages of the participants ranged from 18 to 93 (mean age $=40.02 ; \mathrm{SD}=16.28$ ). Approximately $1.6 \%$ of the women did not complete high school, $34.9 \%$ completed high 
school, 30.2\% completed some college, 18.5\% completed college, and $14.6 \%$ completed more than college. The ethnicity of the sample was Caucasian (58.1\%), Hispanic (15.5\%), Asian/Pacific Islander (9.3\%), African American $(5.4 \%)$, mixed $(4.7 \%)$, and other $(7.0 \%)$. IHLC scores ranged from 12 to 30 on the scale, with participants overall scoring an average of $24.49(\mathrm{SD}=3.55)$.

In mixed model analysis, IHLC did not predict higher baseline cervical cancer knowledge $[b=0.241 ; F(218.29)=$ $0.540, p=0.463]$; women with higher IHLC did not know more about cervical cancer at entry into the study. Also, the interaction of time and IHLC was not significant: IHLC did not predict attainment of more cervical cancer knowledge across time $[b=-0.034 ; F(190.99)=0.026, p=0.871]$. Having higher IHLC did not significantly predict increased cervical cancer knowledge immediately after watching the cervical cancer video $[b=0.208 ; F(96.28)=0.667, p=0.416]$, or at 2 months following the video $[b=0.174 ; F(125.604)=0.286$, $p=0.594]$. There was a significant main effect of time $[b=$ $0.553 ; F(189.81)=13.966, p<0.001]$. The mean of cervical cancer knowledge at baseline $(M=9.46, \mathrm{SD}=1.78)$ was significantly increased at Time Two $[M=11.34, \mathrm{SD}=1.48$; $F(255)=5.273, p=0.022]$, independent of IHLC. However, in this mixed model analysis, there was no significant difference in knowledge at 2-month follow-up $(M=10.44$, $\mathrm{SD}=1.68)$ compared to baseline $[F(252)=0.594, p=0.442]$, or immediately post-intervention $[F(251)=2.25, p=0.134]$.

\section{Discussion}

Deaf women face greater challenges in accessing health information than women without a hearing deficit [7, 8]. They have fewer opportunities to access health knowledge in ASL, and medical providers lack a cultural understanding of this population and its barriers in accessing health information [8, 13, 14, 16, 17]. The Deaf community advocacy leaders in this partnership had expressed the concern that Deaf women may have significantly less access to cancer knowledge and care than hearing women. The ASL cervical cancer education video aimed to address that concern by delivering cancer information in a medium that is easy for this community to assimilate. By administering the MHLC as part of the research design, it was possible to examine the question of whether Deaf women's strength of belief in personal control over their health (i.e., internal health locus of control) would influence their response to the cervical cancer education video.

The results suggested that there was no demonstrable effect of internal health control beliefs on Deaf women's baseline cervical cancer knowledge or knowledge gained after watching the video. IHLC predicted neither baseline levels of cervical cancer knowledge nor knowledge acquisition for Deaf women who viewed the cervical cancer video. However, as this study showed, the women did show increases in knowledge as a result of the educational intervention, supporting the premise that providing education in ASL would be beneficial for the Deaf women.

Although the MHLC is frequently applied to the study of health knowledge and behaviors, in this study, IHLC did not explain the variability in health knowledge among participants, nor did it predict acquisition or retention of health information. However, most participants were quite high on IHLC. A median split was used to characterize participants with higher versus lower IHLC. This is a commonly used method of dividing samples, but it has limitations, especially when scores are negatively skewed, as they were in this sample. Therefore, it is possible that significant relationships between IHLC and health knowledge might be found in a sample with greater variability (i.e., including participants who were more truly external).

This study had several limitations. The sample was relatively small, drawn from a single geographic region, and as with most research studies, the participants were more highly educated than the overall Deaf community. The study did not analyze issues, such as previous experiences with the medical system and demographic factors that can influence health control orientation and behaviors [34]. Also, due to the short time frame, the fairly wide variation in the time until recommended repeat screening based on medical and sexual history, and the lack of data regarding participants' cervical cancer screening practices prior to the study, the study did not assess whether increased knowledge led to improvements in screening practices.

The Deaf community is one of the minority populations frequently neglected in health promotion efforts [20] and research studies. As a result, the Deaf community's concerns, including less than optimal access to health information and care, are rarely addressed. This study showed the importance of conducting research on individual minority communities, especially the Deaf community, rather than assuming that results are translatable to diverse populations. It is increasingly being recognized that members of the Deaf community need to be offered health education material in a way that caters to their linguistic and cultural preferences. Such attention will ultimately empower them to take greater control of their health $[15,16]$.

\section{Conclusion}

IHLC did not predict baseline knowledge or knowledge acquisition or retention for Deaf women who viewed a 
cervical cancer education video. Because the women were able to gain knowledge from an ASL video regardless of their IHLC, IHLC may not be an essential consideration when designing a cancer education program for Deaf women. However, now that there is a validated version of the MHLC in ASL, future studies should evaluate the impact of IHLC on cancer knowledge acquisition and retention with samples that have greater variability on IHLC, as well as examine other types of health-related control beliefs.

Acknowledgments This study was funded by the National Cancer Institute's grants: R25 CA101317, R25 CA108731, R25 CA65745, P30 CA023100, U54 CA132379/U54 CA132384, and U56 CA92079/ U56 CA92081; the National Institutes of Health, National Center on Minority and Health Disparities P60 MD000220 UCSD Comprehensive Research Center in Health Disparities; the National Institute of Child Health and Human Development Grant F31HD056623; a UCSD Academic Senate Grant; the Susan G. Komen for the Cure Foundation, San Diego Affiliate Grant; Alliance Healthcare Foundation Grant; and the California Endowment. The content of this article is solely the responsibility of the authors and does not represent the official views of any of the funding agencies.

The authors also acknowledge the supportive guidance given by I. King Jordan, Ph.D. (Past-President of Gallaudet University); Linda Lytle, Ph.D. and the late Barbara Brauer, Ph.D. (Professors at Gallaudet University); Nancy Bloch (CEO of the National Association of the Deaf); Leslie Elion, J.D. (Executive Director for Deaf Community Services of San Diego, Inc.); Thomas Galey and Raymond Trybus, Ph.D. (past Executive Directors for Deaf Community Services of San Diego, Inc.); Heidi Booth (Director of Health Education Services for Greater Los Angeles Agency on Deafness, Inc.); Scott Roesch, Ph.D. (Associate Professor at San Diego State University); and the members of the Deaf community who participated in this study. The authors also acknowledge the following organizations' assistance with this research study: the Center on Deafness Inland Empire (CODIE) in Riverside; Orange County Deaf Equal Access Foundation (OC DEAF) in Cypress; Deaf Counseling, Advocacy and Referral Agency (DCARA) at the Santa Rosa Outreach Office; Disability Support Programs and Services at San Diego Mesa College; and the National Center on Deafness at California State University, Northridge (CSUN).

Open Access This article is distributed under the terms of the Creative Commons Attribution Noncommercial License which permits any noncommercial use, distribution, and reproduction in any medium, provided the original author(s) and source are credited.

\section{References}

1. California Department of Health Services (2007) Cancer detection programs: every woman counts. http://www.dhs.ca.gov/ps/cdic/ $\mathrm{ccb} / \mathrm{cds} /$ documents/cervicalcancer.pdf. Accessed July 10, 2007

2. Goldie SJ, Gaffikin L, Goldhaber-Fiebert JD, Gordillo-Toba A, Levin C, Mahé C, Wright TC, Alliance for Cervical Cancer Prevention Cost Working Group (2005) Cost-effectiveness of cervical-cancer screening in five developing countries. N Engl J Med 353 (20):2158-2168

3. Newmann SJ, Garner EO (2005) Social inequities along the cervical cancer continuum: a structured review. Canc Causes Contr 16(1):63-70

4. Saslow D, Runowicz CD, Solomon D, Moscicki AB, Smith RA, Eyre HJ, Cohen C, American Cancer Society (2002) American
Cancer Society guidelines for the early detection of cervical neoplasia and cancer. CA Cancer J Clin 52(6):342-362

5. Breitkopf CR, Pearson HC, Breitkopf DM (2005) Poor knowledge regarding the Pap test among low-income women undergoing routine screening. Perspect Sex Reprod Health 37(2): $78-84$

6. Choe S, Lim RS, Clark K, Wang R, Branz P, Sadler GR (2009) The impact of cervical cancer education for deaf women using a video educational tool employing American sign language, open captioning, and graphics. J Cancer Educ 24(1):10-15

7. Sadler G, Galey T, Bovee M (2003) Reducing disparities in the deaf and hard of hearing community's access to health care and social services. Partnersh Perspect 3(1):41-50

8. Ubido J, Huntington J, Warburton D (2002) Inequalities in access to healthcare faced by women who are deaf. Health Soc Care Community 10(4):247-253

9. Allen TE (1994) Who are the deaf and hard-of-hearing students leaving high school and entering postsecondary education? Paper submitted to Pelavin Research Institute as part of the project, A Comprehensive Evaluation of the Postsecondary Educational Opportunities for Students, funded by the U.S. Office of Special Education and Rehabilitative Services. http://gri.gallaudet.edu/ AnnualSurvey/whodeaf.html

10. Bat-Chava Y, Rosen R, Sausa A, Meza C, Shockett S, Deignan E (1999) An evaluation of a college preparatory and readiness program for deaf students. J Rehabil 65(2):51-59

11. Singleton JL, Morgan D, DiGello E, Wiles J, Rivers R (2004) Vocabulary use by low, moderate, and high ASL-proficient writers compared to hearing ESL and monolingual speakers. J Deaf Stud Deaf Educ 9(1):86-103

12. Farber JH, Nakaji MC, Sadler GR (2004) Medical students, deaf patients and cancer. Med Educ 38(11):1201

13. Harner L (1999) Health care delivery and deaf people: practice, problems, and recommendations for change. J Deaf Stud Deaf Educ 4(2):73-110

14. Meador HE, Zazove P (2005) Health care interactions with deaf culture. J Am Board Fam Pract 18(3):218-222

15. Munoz-Baell IM, Ruiz MT (2000) Empowering the deaf. Let the deaf be deaf. J Epidemiol Community Health 54(1):40-44

16. Sadler GR, Gunsauls DC, Huang J, Padden C, Elion L, Galey T, Brauer B, Ko CM (2001) Bringing breast cancer education to Deaf women. J Cancer Educ 16(4):225-228

17. Steinberg AG, Wiggins EA, Barmada CH, Sullivan VJ (2002) Deaf women: experiences and perceptions of healthcare system access. J Womens Health 11(8):729-741

18. Wollin J, Elder R (2003) Mammograms and Pap smears for Australian deaf women. Cancer Nurs 26(5):405-409

19. Iezzoni LI, O'Day BL, Killeen M, Harker H (2004) Communicating about health care: observations from persons who are deaf or hard of hearing. Ann Intern Med 140(5):356-362

20. Woodcock K, Pole JD (2007) Health profile of deaf Canadians: analysis of the Canada Community Health Survey. Can Fam Physician 53(12):2140-2141

21. Steinberg AG, Barnett S, Meador HE, Wiggins EA, Zazove $P$ (2006) Health care system accessibility. Experiences and perceptions of deaf people. J Gen Intern Med 21(3):260-266

22. Brauer BA (1992) The signer effect on MMPI performance of deaf respondents. J Pers Assess 58:380-388

23. Wallston K, Maides S, Wallston B (1976) Health related information seeking as a function of health related locus of control and health value. J Res Pers 10:215-222

24. Bandura A (1997) Self-efficacy: the exercise of control. W.H. Freeman, New York

25. Wallston BS, Wallston KA, Kaplan GD, Maides SA (1976) Development and validation of the health locus of control (HLC) scale. J Consult Clin Psychol 44(4):580-585 
26. Wallston KA (1992) Hocus-pocus, the focus isn't strictly on locus: Rotter's social learning theory modified for health. Cognit Ther Res 16(2):183-199

27. Luszczynska A, Schwarzer R (2005) Multidimensional health locus of control: comments on the construct and its measurement. J Health Psychol 10(5):633-642

28. Wallston KA (2005) The validity of the multidimensional health locus of control scales. J Health Psychol 10(5):623-631

29. Fylan F (1998) Screening for cervical cancer: a review of women's attitudes, knowledge, and behaviour. Br J Gen Pract 48(433):1509 1514

30. Murray M, McMillan C (1993) Social and behavioural predictors of women's cancer screening practices in Northern Ireland. J Public Health Med 15(2):147-153

31. Bazargan M, Bazargan SH, Farooq M, Baker RS (2004) Correlates of cervical cancer screening among underserved Hispanic and African-American women. Prev Med 39(3):465-473
32. Choe S, Lim RSH, Clark K, Wang R, Branz P, Sadler GR (2009) The impact of cervical cancer education for deaf women, using a video educational tool employing American sign language, open captioning, and graphics. J Cancer Educ 24:10-15

33. Wallston KA, Malcarne VL, Flores L (1999) Does God determine your health? The God locus of health control scale. Cognit Ther Res 23(2):131-142

34. Wallston KA, Wallston BS, DeVellis R (1978) Development of the multidimensional health locus of control (MHLC) scales. Health Educ Monogr 6(2):160-170

35. Samady W, Sadler GR, Nakaji M, Malcarne VL, Trybus R, Athale N (2008) Translation of the multidimensional health locus of control scales for users of American sign language. Public Health Nurs 25(5):480-489

36. Athale N, Aldridge A, Malcarne VL, Nakaji M, Samady W, Sadler GR Validity of the multidimensional health locus of control scales in American sign language. J Health Psychol (in press) 